\title{
“DA NOITE PARA O DIA" O ENSINO REMOTO: (RE)INVENÇÕES DE PROFESSORES DURANTE A PANDEMIA
}

ELZANIR DOS SANTOS

https://orcid.org/0000-0001-9026-7953

Universidade Federal da Paraíba

- IDELSUITE DE SOUSA LIMA

https://orcid.org/0000-0002-0418-1561

Universidade Federal da Paraíba

\section{NADIA JANE DE SOUSA}

https://orcid.org/0000-0002-3648-4559

Universidade Federal da Paraíba

RESUMO A pandemia da COVID-19 desvelou, de forma inconteste, problemas estruturais do nosso país, dentre tantos, aqueles ligados às condições precárias de ensino e de aprendizagem. Confrontados diuturnamente por um discurso desvalorizante, os(as) docentes têm assumido, no contexto atual, importância vital no empreendimento de ações que garantam educação a milhões de estudantes. Afetados(as) em sua vida pessoal e profissional, de forma disruptiva, abrangente e intensa, esses(as) profissionais são lançados(as) em um enredo que os(as) convoca a operar mudanças profundas no modo de ser, pensar e fazer seu cotidiano docente, a partir do ensino remoto. Objetivamos, portanto, responder neste artigo, dentre outras, à seguinte questão: como professores(as) têm dado forma e produzido sentidos ao seu ofício no contexto do ensino remoto? Tomamos como aporte teórico Delory-Momberguer (2012, 2016); Souza e Meireles (2018); Passeggi (2010), dentre outros, e assumimos como um de nossos pressupostos que o ato de narrar é parte constitutiva do humano e possibilita aos sujeitos atribuir sentido e interpretar suas experiências. Convidamos professores(as) da educação básica a produzirem narrativas escritas ou orais, sobre o contexto do seu trabalho nas condições atuais, os quais fizeram emergir desafios, estratégias, (re)invenções, aprendizagens e possibilidades para um vir a ser.

Palavras-chave: Ensino remoto. Pandemia. Docentes. Narrativas. (Re) invenções. 
The COVID-19 pandemic unquestionably unveiled structural problems in our country, among many, those linked to the precarious conditions of teaching and learning. Faced daily by a devaluing discourse, teachers have assumed, in the current context, vital importance in undertaking actions that guarantee education to millions of students. Affected in their personal and professional lives, in a disruptive, comprehensive and intense way, these professionals are launched into a plot that calls them out to make profound changes in their way of being, thinking and doing their daily teaching, from remote teaching. Therefore, we aim to answer in this article, among others, the following question: How have teachers shaped and produced meanings to their profession in the context of remote education? We take as a theoretical contribution Delory-Momberguer (2012, 2016); Souza e Meireles (2018); Passeggi (2010), and so forth, and we assume as one of our assumptions that the act of narrating is a constitutive part of the human and allows subjects to attribute meaning and interpret their experiences. We invite teachers of the Basic Education to produce written or oral narratives, about the context of their work in the current conditions, which brought about challenges, strategies, (re)inventions, learning and possibilities for a forthcoming.

Keywords: Remote education. Pandemic. Teachers. Narratives. (Re) inventions

\section{RESUMEN}

\section{"DE LA NOCHE AL DÍA" ENSEÑANZA REMOTA: (RE) INVENCIONES DE LOS MAESTROS DURANTE LA PANDEMIA}

La pandemia de COVID-19 reveló, sin lugar a duda, problemas estructurales en nuestro país, entre otros, los relacionados con las precarias condiciones de la enseñanza y el aprendizaje. Enfrentados diariamente por un discurso devaluado, los docentes han asumido, en el contexto actual, la importancia vital en la realización de acciones que garanticen la educación a millones de estudiantes. Afectados en su vida personal y profesional, de una manera disruptiva, integral e intensa, estos profesionales se lanzan a una trama que los llama a realizar cambios profundos en su forma de ser, pensar y hacer su enseñanza diaria, desde la enseñanza remota. Por lo tanto, nuestro objetivo en este artículo es dar respuesta, entre otras, a la siguiente pregunta: ¿Cómo han dado forma y sentido los maestros a su profe- 
sión en el contexto de la educación remota? Como contribuciones teóricas tomamos los estudios de Delory-Momberguer (2012, 2016); Souza e Meireles (2018); Passeggi (2010), entre otros, y admitimos como uno de nuestros supuestos que el acto de narrar es una parte constitutiva del ser humano, que permite a los sujetos atribuir significado e interpretar sus experiencias. Invitamos así a los maestros de Educación Básica a producir narraciones escritas u orales, sobre el contexto de su trabajo en las condiciones actuales, lo que condujo a la manifestación de desafios, estrategias, (re) inventos, aprendizajes y posibilidades para un futuro.

Palabras clave: Educación remota. Pandemia. Maestros. Narraciones. $(\mathrm{Re})$ invenciones.

\section{Introdução}

Não percamos esse tempo precioso dando deveres. Aproveitemos para pensar se outra escola é possivel. (Tonucci, 2020)

O cenário da pandemia trouxe à luz, de forma dramática e incontestável, as contradições ligadas às desigualdades sociais, econômicas, educacionais, étnicas, de gênero e de classe, que nos obrigam, enquanto sociedade, a fazer perguntas inadiáveis, no que diz respeito aos caminhos para encontrar as soluções que respeitem, acima de tudo, o direito a condições dignas de vida.

Entretanto, diariamente temos assistido, do ponto de vista das instâncias gestoras da política brasileira, ao descaso, à negligência ou aposta em soluções que ferem os princípios do direito a ter direito, por parte de todos(as). Ganha ainda mais evidência a degradação das condições de trabalho de professores(as), particularmente da educação básica, traduzidas, entre outras manifestações, pelo número de estudantes em cada turma, dificultando que aqueles que mais precisam tenham mais atenção; a ausência de tempo para estudo e aprendizagem sobre uso das novas tecnologias e, mais ainda, as inadequadas condições de acesso e uso da internet.
De um contexto no qual se confrontam rotineiramente com discursos que os desvalorizam e os desqualificam, durante a pandemia, os(as) professores/as são instados, mais do que nunca, a estarem na "linha de frente", cuidando da garantia do direito à educação por parte de milhões de estudantes matriculados(as) nas escolas públicas e privadas brasileiras.

A saída encontrada pelos órgãos da gestão educacional, para sanar, minimamente, os prejuízos acarretados pela pandemia e consequente necessidade do isolamento social, foi o "ensino remoto", as "aulas on-line", ou o "ensino a distância", conforme têm sido denominadas as alternativas ao ensino presencial. Tempo, espaço e currículo precisaram, de repente, ser reinventados, embora, em muitos aspectos, essa "reinvenção" seja a continuidade de práticas que já se apresentavam frágeis no ensino presencial.

Confrontados(as) à urgência para dar continuidade ao ensino e aprendizagem, os(as) professores(as) se veem diante da obrigação de redefinir, ressignificar, reinventar e "desaprender" muitas das suas certezas teóricas e metodológicas quanto ao seu fazer. Esse tempo marcado pelo ineditismo, urgência e potência 
em experiências de aprendizagem, interpela a todos(as) - sociedade em geral, profissionais da educação e pesquisadores, em particular - a compreendê-lo para propor caminhos que apostem em um presente/futuro melhor em humanidade.

Assim, neste artigo, buscamos responder, às seguintes questões: como professores(as) da educação básica têm dado forma e significado ao vivido no contexto do ensino remoto? Quais enfrentamentos, desafios, estratégias têm atravessado o cotidiano do seu fazer? Que aprendizagens e possibilidades emergem deste espaço/tempo e que podem conduzir os(as) docentes a processos de (re)invenção de si e do seu fazer?

Partindo do pressuposto de que o ato de narrar é humano (PASSEGGI, 2010; DELORYMOMBERGUER, 2016) e possibilita aos sujeitos atribuir sentido e interpretar suas experiências, convidamos professores(as) da educação básica, de escolas públicas e privadas do estado do Ceará e da Paraíba a produzirem relatos escritos ou orais, sobre o contexto do seu trabalho no ensino remoto. 0 narrar-se possibilitou aos(às) docentes uma parada, um distanciamento, um tempo - ainda que breve - de reflexão sobre seu cotidiano docente, sua interpretação das experiências e os sentidos atribuídos às reconfigurações promovidas pela exigência do ensino remoto. Os(as) professores(as) trouxeram à luz o cotidiano do seu trabalho, seus desafios e sua capacidade (re) inventiva de produzir estratégias de superação e inversão de lógicas de ações; a dimensão do sensivel, ensejada pela interpretação das suas condições emocionais, neste contexto de risco iminente de morte real ou simbólica; aprendizagens e possibilidades para um vir a ser.

Desse modo, o texto está estruturado apresentando uma breve contextualização do cenário atual, destacando aspectos ligados ao campo da educação. Além disso, argumenta- mos sobre a pertinência da pesquisa com narrativas para entender como professores(as) interpretam suas experiências emergentes nesse contexto de pandemia. Em seguida, trazemos as análises das narrativas docentes, enfocando desafios, enfrentamentos, estratégias e aprendizagens e possibilidades ensejadas pelo seu fazer no ensino remoto. Nas considerações finais, pontuamos os aspectos centrais anunciados nas narrativas dos(as) professores(as) e defendemos a urgência de se fazer perguntas fundamentais, na direção de uma educação mais humana, que cuide e atribua importância igual a todas as vidas.

\section{O contexto da pandemia e suas implicações para a educação escolar e os modos de ser/fazer docente}

A pandemia da COVID-19 nos lançou, de forma disruptiva, num cenário de incertezas, de medo, de redefinição das nossas relações com nós mesmos, com os outros e com o mundo. Ela instaurou um tempo de suspensão, de reflexões, de problematizações, um tempo de perguntas (quais perguntas?) orientadas, sobretudo, para o campo da saúde, da economia e da educação.

$\mathrm{Na}$ saúde, as indagações que se impõem em nosso cotidiano assombroso, são: “Quais os índices de contágio e letalidade alcançados, hoje?"; "Como nos proteger melhor e aos nossos?"; "Quando teremos uma vacina?"; "Quando finda o isolamento social?". No campo da economia, empresários têm tentado colocar suas urgências de lucro acima de tudo e de todos, forjando um falso e perverso dilema: "Como ficará a economia e o desenvolvimento do país se os(as) trabalhadores(as) continuarem sem trabalhar, em decorrência do isolamento social?". Para a classe trabalhadora, por sua vez, cria-se uma impiedosa dicotomia: 
"Mantenho minha vida/saúde ou meu emprego?". No campo da educação, as interrogações hegemônicas - dos empresários da educação aos professores - são: "Como repor o calendário letivo, tendo em vista a suspensão das aulas presenciais?"; "Como manter a aprendizagem dos estudantes para que não percam o ano letivo?"

Considerando que o contexto atual desmascarou de forma irrefutável o problema das desigualdades de acesso, particularmente, aos bens da saúde e da educação, as questões postas anteriormente escamoteiam e adiam a pergunta fundamental: “Como garantir que todos(as) tenham acesso a uma vida digna, uma vida que valha a pena ser vivida, incluindo condições justas de saúde, trabalho e educação?".

Apesar disso, o que vemos são soluções idealizadas e implementadas na lógica tão conhecida e ineficaz da pressa, do improviso, da superficialidade e da reificação das desigualdades sociais, econômicas e educacionais. As saídas encontradas expressam, portanto, uma tentativa de mudança na continuidade. Reproduzem-se e se agravam os problemas a partir de um argumento, enunciado por empresários da educação e setores do governo - de que “afinal precisamos fazer alguma coisa, pois não será agora que iremos resolver o problema da equidade". Aceitar, naturalizar e legitimar as desigualdades é, no entanto, uma forma de negar e desacreditar que o direito à educação é um direito de todos, "pondo em crise todo o humanismo social e pedagógico que inspirou a defesa do direito de todo cidadão à educação, à humanização" (ARROYO, 2015, p. 22). Deixa-se de trazer ao debate uma indagação fundamental sobre como é possivel melhorar e/ou ampliar o acesso às novas tecnologias, por parte de professores(as) e alunos(as).

É consensual a defesa de que a escola tem uma responsabilidade fundamental na ges- tão da educabilidade dos sujeitos aprendentes, especialmente neste contexto. Assim, ela foi convocada pelo Ministério da Educação e Secretarias da Educação, a cumprir sua tarefa mediante determinadas prescrições ${ }^{1}$, propondo soluções, tendo em vista dar prosseguimento às atividades de aprendizagem.

A saída encontrada para garantir o "direito à aprendizagem" ou "vínculo com a escola" foi o "ensino remoto"2. Essa alternativa exigiu um diagnóstico das condições dos(as) estudantes para tal empreendimento e o cenário desnudado, de forma que não é mais possivel disfarçar, foi a irrefutável desigualdade de acesso aos meios tecnológicos, resultantes de outras tantas injustiças que atingem aos(as) filhos(as) da classe trabalhadora. Parte significativa dos(as) estudantes da rede de ensino brasileira não tem nenhum acesso ou não dispõe de condições adequadas de uso da internet e tecnologias digitais. Assim,

$20 \%$ dos domicílios brasileiros - o equivalente a 17 milhões de unidades residenciais - não estão conectados à internet, o que impossibilita o acesso de alunos ao material de ensino a distância disponibilizado em seus portais por muitas escolas públicas do ensino fundamental e do ensino médio. [...] Mais de $40 \%$ das residências não possuem computador e, entre os que possuem, poucos possuem softwares atualizados e capacidade de armazenamento. E são de uso comum de 3 ou mais pessoas (COLEMAX, 2020, p. 16).

Embora as orientações oficiais tenham amparo na justificativa da garantia do direito à educação, as soluções encontradas apontam na direção oposta, uma vez que, na gramática escolar da pandemia, a aprendizagem é com-

1 Cf.: Parecer CNE/CP no 9/2020-MEC (BRASIL, 2020).

2 Esta denominação "ensino remoto" é considerada mais adequada que "ensino a distância", em virtude de que esta segunda modalidade tem uma regulamentação, estrutura e projeto pedagógico específicos, divergindo da primeira que tem como marca o caráter de emergência, improviso e diversidade de formas para sua realização. 
preendida, em muitos casos, circunscrita à realização e entrega de atividades, particularmente, para aqueles estudantes que não têm acesso às novas tecnologias. Desconsidera-se, dessa forma, todos os demais aspectos ligados ao processo, seu sentido amplo e humanístico de prática social, de mediação, de interação, de coletividade.

Além disso, em face do quadro dramático de agravamento do desemprego, da precarização das condições de moradia, saúde e alimentação, ao limitar-se as preocupações ao cumprimento do calendário letivo e avaliações, o vínculo entre educação e vida, ensino e aprendizagem e condições para sua realização têm sido reiteradamente negligenciados no discurso e prática das instâncias da política educacional, muitas vezes, em nome de interesses que intencionam esvaziar a escola de sua função de bem público (CÁSSIO; CARNEIRO, 2020, p. 03), isto é, de seu papel de garantir, democraticamente, o acesso à educação.

Os(as) professores(as), que, no caso brasileiro, somam 2,2 milhões, em 180,6 mil escolas (COLEMAX, 2020), são conclamados(as) a serem protagonistas nesta tarefa de retomada das atividades pedagógicas, mas, apenas como implementadores de ações, sem participação nas decisões e em moldes que, em muitas situações, sacrificam a característica principal do seu trabalho, assentada na mediação pedagógica, em face de que parte significativa dos(as) estudantes não tem como acessar as aulas on-line. Muitos(as) desses(as) profissionais tiveram que, de forma repentina, conjugar tarefas domésticas, maternidade, cuidados de familiares e ensino remoto. Suas condições de trabalho foram, portanto, drasticamente modificadas e precarizadas. No caso de docentes da rede privada ou daqueles(as) que não são efetivados(as) na rede pública, soma-se ao risco da saúde, o risco do desemprego.
Partindo desse contexto e do entendimento da importância política e epistemológica de envidarmos esforços para compreendê-lo, buscamos responder, a partir de narrativas de professores(as), às seguintes indagações: “Como docentes da educação básica estão (re) significando, (re)inventando e (re)existindo em seu fazer docente no contexto do ensino remoto?"; "Como elaboram e interpretam, na narrativa de si e do seu fazer, o que experimentam em termos de desafios e estratégias, neste contexto de excepcionalidade?"; "O que apontam como aprendizagem e possibilidades para um vir a ser?".

As análises que ora apresentamos se respaldam no campo teórico-metodológico das narrativas autobiográficas, em face da sua fecundidade, em abordar a temática da formação e trabalho docente, numa perspectiva que valoriza a subjetividade, a dimensão singular-plural, as interpretações e significados atribuídos pelos sujeitos que narram as suas experiências.

\section{As narrativas (auto)biográficas e sua pertinência à produção e apreensão de sentidos atribuídos às experiências educacionais}

Para compreender algumas dimensões do trabalho docente, isto é, como os professores estão interpretando e avaliando suas experiências presentes, como estão (re)inventando seu fazer, a abordagem mais pertinente a este intento é a pesquisa (auto)biográfica, em face de ter como marca o respeito ao sujeito, ao seu modo de ver e dizer sua existência. Segundo Souza e Meireles (2018, p. 285),

[...] no campo educacional, as pesquisas (auto) biográficas nascem e se articulam a partir de princípios da pesquisa qualitativa e da constituição de outros modos de ver/escutar/narrar a vida e as aprendizagens-experiências que se 
inscrevem nos domínios da formação dos adultos, de professores em processos de formação inicial ou continuada, mas também das formas diversas que as narrativas têm assumido no cenário contemporâneo.

Pesquisar, nessa abordagem, requer uma abertura, uma ampliação e engajamento de sentidos outros - ver, escutar e falar/narrar afastando-se de paradigmas positivistas, os quais reivindicam a predominância do olhar, do observar.

A escolha pela pesquisa narrativa é da maior relevância, tendo em vista que essa abordagem tem como um de seus pressupostos a dimensão da reflexividade humana. Dessa forma, o ato de narrar tem, como uma de suas qualidades, o engajamento do autor da narrativa em um processo de elaboração, de estruturação e atribuição de sentidos àquilo que vive, a partir de uma tripla temporalidade, isto é, um antes, durante e depois, ainda que isto não signifique instaurar uma cronologia. Assumimos, portanto, que

o indivíduo humano vive cada instante de sua vida como o momento de uma história: história de um instante, história de uma hora, de um dia, de uma vida. Algo começa, se desenrola, chega a seu termo numa sucessão, superposição, empilhamento indefinido de episódios e peripécias, de provações e experiências (DELORY-MOMBERGUER, 2012, p. 525).

É válido sublinhar que não se trata de supor que a história ou a narrativa de vida preexiste à narração. É o ato de contar, de narrar, o qual implica em trazer à luz personagens, contextos, relações e temporalidades, mediado por um discurso explicativo, descritivo, avaliativo e interpretativo, que configura a história daquele que conta. Conforme Passeggi e Rocha (2012, p. 40), "é com base em padrões narrativos que organizamos nossas memórias, que clarificamos nossas intenções, nos constituímos como pessoa e nos apropriamos de nossas identidades".
O trabalho com a pesquisa (auto)biográfica, seja na dimensão da pesquisa, e/ou da formação, institui-se como uma escolha não circunscrita a opções teórico-metodológicas e epistemológicas, mas implica em demarcar um posicionamento, uma decisão política, uma vez que ela assume como princípio o respeito à dimensão subjetiva, à voz dos sujeitos, ao que eles têm a dizer sobre si e suas experiências, ao modo como interpretam sua existência. Nessa ótica, Souza (2014, p. 41) reivindica que essa abordagem,

mais do que invadir a vida humana, parte de princípios deontológicos e busca assegurar a vida, ao abrir espaços para socializações e partilhas de modos próprios de como os sujeitos vivem, se desenvolvem, aprendem, enfrentam conflitos, buscam alternativas para superar as adversidades da vida frente aos processos de inclusão/exclusão social.

Um conceito fundamental para a compreensão desse campo é a noção de "biografização", a qual pode ser entendida como "escrita da vida" em face da elaboração e interpretação da experiência. Segundo Delory-Momberguer (2012, 2016), o biográfico remete ao conjunto de representações e de construções segundo as quais os seres humanos percebem sua existência. Para esta autora, o biografar-se não se limita ao discurso, na sua versão oral ou escrita, mas diz respeito a

[...] uma atitude mental e comportamental, a
uma forma de compreensão e de estruturação
da experiência e da ação, exercendo-se de for-
ma constante na relação do homem com sua
vivência e com o mundo que o rodeia (DELORY-
MOMBERGUER, 2012, p. 524).

As narrativas (auto)biográficas, construídas em processo de pesquisa ou em práticas de formação, centram-se nas trajetórias, percursos e/ou em experiências dos sujeitos. Tais itinerários ou acontecimentos individuais ou coletivos são atravessados por dimensões tem- 
porais, espaciais, históricas, culturais, sociais e subjetivas, em face das reflexões e análises construídas por cada um, ao narrar oralmente ou na escrita sobre si. Nessa ótica, deslegitima-se o argumento, ainda vigente, de que essa abordagem de pesquisa prioriza a dimensão individual em detrimento do caráter social e coletivo amalgamado nas itinerâncias dos sujeitos. Ora, segundo Ferrarotti, "se nós somos, se todo indivíduo é a reapropriação singular do universal social e histórico que o rodeia, podemos conhecer o social a partir da especificidade irredutivel de uma práxis individual" (FERRAROTI, 2010, p. 27).

A narrativa (auto)biográfica constitui uma forma primária e essencial de que os sujeitos lançam mão intencionando organizar suas experiências, permitindo atribuir sentidos ao que é narrado e contado aos outros. Por isso, segundo Hubermam (2005), mais que outras formas de expressão, ela se converte no meio mais adequado quando se trata de investigar os docentes, tanto para captar a maneira pela qual constituem seu autoconhecimento, como para solicitar que enunciem o sentido pessoal, organizando sua experiência a partir de uma dimensão temporal.

Neste paradigma investigativo e/ou formativo, outro pressuposto-chave conduz à noção de que o sujeito é passivel de ser condicionado, influenciado, perpassado pelos condicionantes sociais, ao mesmo tempo em que se constitui agente de mudança, de transformação da realidade. Emerge daí mais um fator da sua pertinência à pesquisa com professores(as). Dessa forma, Passeggi (2016, p. 73) defende que o sujeito é capaz de refletir:

[...] para avaliar o que a cultura the oferece e 'projetar alternativas' para (sobre)viver nessa cultura e, eventualmente, transformá-la. Adotar tal disposição como um princípio epistemológico e político permite conceber os professores como seres capazes de reconhecer o poder da cultura sobre eles, mas também de avaliar e pro- jetar alternativas para viver melhor e contribuir para que outros também vivam melhor nas suas relações com o poder que emana da cultura.

Por seu caráter de abertura à compreensão da realidade, privilegiando as vozes e silêncios dos sujeitos pela via da escuta, do olhar e do diálogo, a narrativa se torna esse modo privilegiado “para se apreender e se compreender a impermanência do ser, a fluidez dos conhecimentos e a plasticidade da experiência humana em contextos cada vez mais amplos e mais diversificados" (PASSEGGI; ROCHA, 2012, p. 40).

Assim, buscamos compreender as (re)invenções, (re)existências e (re)significações construídas por esses sujeitos, na luta diária pela vida e pela manutenção ética do seu fazer docente. As fontes utilizadas são relatos produzidos/mediados por WhatsApp - oral via áudio e escrito - e por e-mail, de 13 docentes que atuam na educação básica das redes públicas do estado do Ceará (seis colaboradoras) e do estado da Paraíba (sete colaboradores(as)). 0 grupo é formado por dois professores - os quais atuam no ensino médio - e onze professoras, dentre as quais duas atuam na educação infantil. Quanto ao local de atuação, assim estão divididos: três são do município de Fortaleza (CE); três vinculam-se a escolas da sede do município de Icó, interior do Ceará; e sete têm vínculo com a rede pública de João Pessoa.

A opção por envolver professores dos dois estados mencionados se deve ao critério do acesso aos participantes e em face da pressuposição de que, na ausência de orientações sistemáticas do Ministério da Educação, mesmo após mais de um mês do fechamento das escolas, houvesse diferenças significativas quanto aos contextos, condições de trabalho e desafios impostos aos(às) docentes na operacionalização do ensino remoto. Hipótese que não se confirmou. Os tópicos a seguir sublinham, respectivamente, desafios, enfrenta- 
mentos e estratégias, aprendizagens e possibilidades do que-fazer docente em tempos de pandemia.

\section{"Começamos sem nenhuma}

orientação": desafios, (re)

existências e (re)invenções

\section{docentes no ensino remoto}

O contexto histórico, social, econômico decorrente da pandemia nos tem obrigado a reorientar percursos, com marcas profundas em nossas trajetórias de vida, mas que solicita que não desconsideremos sua "pedagogia", a qual pode nos ensinar muito sobre nossas condutas, nossas atitudes, nossa visão de mundo, nossos sonhos (SANTOS, 2020). No presente, esse cenário impõe que tomemos decisões importantes para dar sequência à nossa (re)existência.

A educação escolar ocupa lugar central em nossas vidas, seja como família de crianças e jovens, seja como estudantes, seja como profissionais que atuam nas escolas. Os(as) professores(as), "da noite para o dia", tiveram que se descolar e deslocar-se de um cotidiano relativamente estável de preparação, realização e acompanhamento de aulas, para uma configuração de ensino e aprendizagem bastante diversa: o ensino remoto. Portanto, na atualidade, é imperativo que saibam lidar com os inúmeros desafios e encontrem saídas para viabilizar a continuidade do seu ofício.

Inventar um novo jeito de ministrar aula, sem um projeto de ação mais detalhado e sem as condições efetivas de trabalho, acaba por confirmar um arranjo que foi se desenvolvendo semelhante a "trocar o pneu com o carro em movimento", atropelando um percurso que vinha sendo vivenciado no decorrer do período letivo. 0 depoimento da professora, citado a seguir, caracteriza esse desatino:
Nós professores nos deparamos da 'noite para o dia' com uma necessidade de prosseguir o ensino, com uma maneira de ensinar totalmente dependente da tecnologia. Essa 'forma de ensinar' nos lançou inúmeros desafios, superáveis ou não (Prof.a 07).

A expressão "da noite para o dia" denota não apenas o impacto causado pela surpresa da professora em exercer a docência em outro formato, mas revela também uma ruptura com o seu passado, com as estratégias utilizadas em outros momentos e que, no presente, não podem mais fazer parte da sua rotina, como fora um dia. A pandemia nos lembra que as existências não lineares, nem coerentes em si mesmas, podem ser "sacudidas por forças coletivas que reorientam seus percursos de uma maneira imprevista e, geralmente incontrolável" (BERTAUX, 2010, p. 49).

$O$ desafio expresso no relato da professora associa a necessidade de prosseguir o ensino com tensas e intensas relações entre o que vinha sendo realizado e o que se apresenta para ser feito de imediato e na urgência, com a instabilidade da situação pandêmica e suas dimensões sociais, pelas quais passam os sujeitos da escola. Portanto, o cenário atual convida a mudanças significativas nos modos de fazer, ver, sentir e dizer a profissão docente, implicando em reconstruções identitárias imprescindiveis.

A temporalidade circunstanciada pela ruptura na trajetória do trabalho docente dá lugar ao ensino remoto com consequências individuais, coletivas e sociais. Revela, por sua vez, a forma como as instâncias educacionais concebem a escola e sua cultura, os(as) educadores(as) e, particularmente, os(as) estudantes. Esse mal-estar com a instituição é destacado nas falas das professoras que se sentem desamparadas:

Começamos sem nenhuma orientação por parte da Secretaria de Educação do Município ou da 
gestão, em relação a darmos continuidade ao trabalho com as crianças (Prof.a 10).

O ensino remoto durante a pandemia veio para nós educadores como um desafio a ser enfrentado sem nenhuma formação continuada ou planejamento anterior. $\mathrm{Na}$ realidade, pegounos de surpresa para ser executado sem algum preparo e para aqueles professores que não tinham habilidades com as tecnologias e uso de ferramentas de comunicação ou com o acesso das redes sociais, o desafio se tornou gigantesco (Prof.a 04).

Tais depoimentos ilustram bem as condições estruturais e a ausência de um processo formativo, minimamente possivel, para o enfrentamento a uma nova modalidade de trabalho e a uma dinâmica de organização curricular que envolve não apenas recursos tecnológicos, mas sobretudo, lidar com vidas, com pessoas em situações de mudança.

Outro aspecto enunciado pelos(as) professores(as) diz respeito à pressão dos organismos educacionais, no que tange ao currículo, revestidos de uma pressa, de uma preocupação exacerbada com o cumprimento dos dias letivos, em detrimento das questões ligadas à vida, às condições de existência e de efetivação da continuidade do processo de ensino e aprendizagem. Os(as) professores(as) se percebem num dilema, pois têm que cumprir "a todo custo" as exigências de instâncias superiores, ainda que discordem de parte das deliberações. Os depoimentos a seguir são ilustrativos:

Nós deveríamos sim, ter esse acesso, procurar, saber como está, mais cuidado emocional e não se preocupar tanto com os números, né? (Prof.a 06)

Pelo que eu tô percebendo vai ser contado como hora aula, no caso do fundamental, muita, muita coisa vai ser perdida, né. E aí ele vai passar por um outro ano sem ter vivenciado de fato, sem ter construído aquela habilidade, aquele conhecimento do modo mais adequado e isso pode ser... Ele [estudante] pode vir a sentir maiores dificuldades no ano seguinte, enfim... vira uma bola de neve. Então é bem complicado. Eu acho que a gente deve sim, manter o laço, manter o contato, né, o vínculo com aluno, a gente deve sim sugerir atividades que ocupem o tempo deles e ocupem com qualidade, ocupem com algo que possa até estimular e desenvolver o laço dele com a família, mas contar isso como hora aula, eu acho que é bem complicado, não deveria ser, né (Prof.a 02).

Exercer a docência na pandemia exige, portanto, repensar o currículo estabelecido, questionar a validade das prescrições e diretrizes curriculares para, assim, compreender o outro, seu contexto e sua história, com vistas a promover a inclusão social. De acordo com Goodson (2007, p. 242), “precisamos mudar de um currículo prescritivo para um currículo como identidade narrativa; de uma aprendizagem cognitiva prescrita para uma aprendizagem narrativa de gerenciamento da vida". Para esse autor, a aprendizagem está relacionada com a história de vida dos sujeitos, com o contexto em que estão inseridos e o currículo também pode tornar possivel a aposta em um novo futuro social. Em suas palavras:

No novo futuro social devemos esperar que o currículo se comprometa com as missões, paixões e propósitos que as pessoas articulam em suas vidas. Isto seria verdadeiramente um currículo para empoderamento. Passar da aprendizagem prescritiva autoritária e primária para uma aprendizagem narrativa e terciária poderia transformar nossas instituições educacionais e fazê-las cumprir sua antiga promessa de ajudar a mudar o futuro social de seus alunos. (GOODSON, 2007, p. 251)

Nessa perspectiva, tomar conta das pessoas é o mote que se anuncia, quer na pandemia ou fora dela. É preciso tomar conta, cuidar de si e dos outros, uma vez que escola é, por natureza, um lugar para cuidar das pessoas, para possibilitar que estas vislumbrem novos horizontes. 
Um dos maiores desafios elencados pelos(as) professores(as) colaboradores é o fato de que uma parte significativa dos estudantes da escola pública está com dificuldade de acompanhar ou, o que é ainda mais grave: está completamente ausente do processo, decorrente da ausência de recursos tecnológicos. $A$ precariedade do acesso e acompanhamento das atividades remotas assume diversas nuances: não há acompanhamento dos pais ou responsáveis, seja porque estes estão trabalhando, seja por não saberem orientar as atividades; só há disponibilidade de um aparelho de celular em casa; não há internet de qualidade que viabilize em melhores condições a realização das atividades. Os depoimentos a seguir são elucidativos, nesse sentido:

Tem alguns pais que infelizmente não podem estar de quarentena, então alguns estão trabaIhando, então só têm acesso à tarde ou às vezes trabalham o dia todo e só podem fazer à noite com a criança [...] as dificuldades são as mais diversas possiveis, desde o celular tá ruim, tá com a memória cheia, não consegue abrir os vídeos (Prof.a 02).

Tem muito aluno que a gente não sabe como tá, não sabe as condições familiares e não tem tido contato e aí tem até professor que tá pensando em passar na casa desses alunos pra tentar algum contato com eles (Prof. 05).

Diante dos inúmeros enfrentamentos, requer-se que a escola esteja menos preocupada com os conteúdos e mais voltada em manter e/ou ampliar os vínculos com o(a)s estudantes e suas famílias, seus entornos, suas vidas. 0 depoimento do professor 05 evidencia o esforço que escola e professores, apesar de tudo, têm empenhado visando garantir o direito à educação, ainda que infelizmente não consigam chegar a todos. Segundo Cássio e Carneiro (2020, p. 3),

A pandemia evidencia não apenas a vulnerabilidade existencial das vidas humanas, mas a nossa obscena e naturalizada desigualdade de acesso a bens públicos. Bens públicos são, por definição, não rivais e não excluíveis. Isso quer dizer que quando um bem público é consumido, a sua quantidade disponivel para as outras pessoas não diminui. Saúde e educação são bens públicos por excelência. Ou, pelo menos, deveriam ser.

Apesar dos desafios, dilemas, dificuldades que emergem do contexto pandêmico, os(as) docentes (re)inventam formas de resistir e (re) existir aos empecilhos, principalmente, no que concerne à distância física dos alunos e suas famílias. Os trechos citados, a seguir, destacam parte da interação elencada pelas professoras:

busco sempre interagir com os(as) estudantes ou os pais. Sim, porque agora os pais assistem nossas aulas, escutam nossos áudios e muitos até interagem comigo e com os demais colegas professores na intenção de acompanhar (Prof.a 07).

Os pais, em sua maioria, têm dado feedbacks positivos quanto a nossa postura e preocupação com as crianças e estão bastante envolvidos. Alguns deles já até disseram que também estão se sentindo beneficiados com as atividades, pois estão aprendendo também, como se tivessem voltado a estudar. Fico muito feliz com a responsividade deles (Prof.a 10).

Portanto, como estratégias e como resistência às dificuldades de dar continuidade aos processos de ensino e aprendizagem, a ação docente vai sendo modificada, (re)inventada, sublinhando uma dinâmica que caracteriza a maneira como cada um vai configurando o alcance da sua atuação, pois as relações estabelecidas mobilizam interações mais abrangentes com as famílias e a escola, ampliando sua função de educabilidade. Ensinar também aos pais emerge como saída para dar continuidade à mediação pedagógica, essencial à aprendizagem.

Sob essa lógica, o trabalho docente é, então, partilhado com os pais, permitindo que 
os(as) professores(as) sintam, percebam e apreendam experiências de vida de uma diversidade de sujeitos envolvidos no ensino remoto. Socializam acontecimentos, relatos, expectativas e, ao narrarem esses fatos, ressignificam seus saberes, "pois os sentidos produzidos pelos sujeitos sobre si e sobre seus mundos sociais revelam modos de apreensão e interpretação do vivido" (SOUZA; MEIRELES, 2018 , p. 290). Portanto, as relações entre professores(as) e famílias têm um rico potencial para serem retomadas num tempo pós-pandemia, instaurando-se assim uma rica oportunidade de abertura a aprendizagens favorecidas pelos duros ensinamentos ocasionados pelo atual contexto.

Ao constatar essa incorporação ao trabalho, algumas iniciativas são adotadas comportando uma variedade de ações sobre outras maneiras de realizar a docência na coexistência da quarentena, possibilitando aos(às) professores(as) (re)inventar-se, reconstruir-se em seus processos identitários, uma vez que as mudanças ensejadas pelo ensino remoto implicam novos modos de se relacionar com o imaginário da sua profissão, consigo mesmo, com os(as) estudantes e com as famílias. Os relatos a seguir dão testemunho dessa condição:

Está sendo um desafio, mas é inevitável, não poderíamos ficar sem contato com nossos alunos por tanto tempo, isso iria deixá-los desmotivados e prejudicaria o processo de aprendizagem. [...] mantenho sempre o contato, via WhatsApp ou ligação telefônica, perguntando os motivos e incentivando-os a permanecerem com essa rotina (Prof.a 08).

As estratégias que estou usando é tentar estar o mais próximo possivel deles. Então, eu faço ligações, eu faço pra que aqueles que podem fazer, eu faço videochamada pelo WhatsApp, pra que tenha esse contato comigo e também com os colegas (Prof.a 06).

Em face de todos os empecilhos decorrentes da pandemia e transpostos ao ensino remoto, não há como desconsiderar a necessidade de motivação e de proximidade para desenvolvimento de vínculos entre estudantes e professores(as). Os relatos demonstram que, em virtude do isolamento social e das dificuldades apresentadas pelos(as) alunos(as), tem sido necessário o estreitamento de laços e uma aproximação maior através dos contatos via recursos tecnológicos, para acompanhar os(as) discentes.

Certamente, o engajamento e a atenção individualizada resultam em uma maior aproximação para a manutenção de uma rotina de estudos e se tornam imprescindiveis para acompanhar os itinerários dos(as) estudantes. Importa destacar que esse aspecto há décadas é defendido e reivindicado como pressuposto para um ensino mais qualificado. Entretanto, pelas condições de trabalho docente conformadas em nosso país, isso somente está sendo viabilizado neste cenário porque se impõe para muitos(as) como a única forma possivel para dar materialidade ao sentido da docência, ou seja, criar as condições para que os(as) estudantes aprendam, o que exige apostas em seu próprio trabalho, como está evidenciado na fala das professoras:

Para isso, reservo a maior parte do dia, estou disponibilizando mais tempo com esse ensino (Prof.a 08).

Eu fico o dia inteiro recebendo as devolutivas dos alunos, os questionamentos, as dúvidas. Para atender às demandas, eu tive que me adaptar à realidade deles. De certa forma, eu fico disponivel o dia todo para atendê-los (Prof.a 09).

De forma inconteste, as falas dos(as) professores(as) revelam que o trabalho docente se avoluma de forma intensa na realização da prática pedagógica a distância, cujos horários são demasiadamente ampliados pelas condições de acesso tecnológico e/ou apoio familiar. Ao tempo em que se materializa essa sobrecarga, os(as) professores(as) articulam sig- 
nificados, alternando emoções e sentimentos que ultrapassam os fatos vividos na interface das continuidades e permanências do fazer docente no ensino remoto.

Os(as) professores(as) ainda são instados a saber lidar, não só com as emoções dos(as) discentes e de suas famílias, mas igualmente com as próprias emoções, angústias e ansiedade. $E$, nesse intento, continuam praticamente sozinhos. A eles é tributada a responsabilidade de cuidar, de motivar, mas quem cuida do cuidador? Algumas Secretarias de Educação disponibilizaram serviços de apoio psicológico aos(às) discentes, enquanto os(as) professores(as) foram lançados à própria sorte.

Os depoimentos a seguir são emblemáticos do quanto esses(as) profissionais estão sendo afetados pelo cenário dramático do ensino emergencial:

Tem também [angústia] porque a gente não consegue chegar a todos (Prof.a 02).

[...] entra muito essa questão de emocional do isolamento de não ver pessoas... tudo... e só por uma plataforma digital [...] (Prof. 01).

São muitas coisas que a gente tenta fazer pra dar conta, mas ao mesmo tempo a gente se sente meio de mãos atadas, né? Porque a gente não pode tá lá, não pode chegar junto, não pode dar um apoio de perto [...] (Prof. 04).

Outros depoimentos também reforçam os conflitos vivenciados pelos(as) educadores(as), tais como:

o contato diário com muitas informações negativas nos causam sentimento de impotência, a preocupação com as crianças e os pais (que vivem em situação precária) me deixa muito pra baixo e, às vezes, não consigo forças para me concentrar e produzir algo de qualidade (Prof.a 10).

[...] não acredito no resultado dessas atividades remotas, acho tudo inutilidade, sinto-me obrigada a compactuar com uma farsa, e ao mesmo tempo isso me dá uma sensação de culpa, pois não temos resposta para o que fazer, ou seja, se não participo, não me importo com meus alunos, pois eles supostamente estão numa situação ainda mais dificil que a minha. Além do mais, estou em casa recebendo e preciso 'trabalhar' ou mostrar serviço, mesmo que inútil (Prof.a 11).

Tais sentimentos ressoam a afirmação de Nóvoa (2002, p. 24) de que: “os professores vivem num espaço carregado de afectos, sentimentos e conflitos. Quantas vezes preferiam não se envolver... Mas, sabem que tal distanciamento seria a negação do seu próprio trabalho".

De um lado os relatos dimensionam uma das marcas da docência: seu caráter relacional e, portanto, sua indissociabilidade com o sensível, com a afetividade, com as emoções. De outro, apontam que o cuidado com os(as) professores se torna necessário e inadiável, sob pena de que os prejuízos acarretados por esse cenário sejam ainda mais dramáticos e de longo prazo.

\section{"Estamos abrindo novos caminhos"}

Apesar de todo o cenário desolador, em suas narrativas os(as) docentes evidenciam sua "biograficidade" (DELORY-MOMBERGUER, 2016), isto é, sua capacidade de refletir, interpretar e elaborar sua experiência, trazendo à luz, por sua vez, a marca humana do inacabamento, na forma da sua vocação para aprender, para metamorfosear as experiências, os percursos, os percalços. É nessa direção que professores(as) convertem, invertem, (re)inventam sentidos, olhares e modos de dizer o que vivem. No que contam, surgem ganhos, situações imprevisíveis e afirmativas, aprendizagens e projeções para um devir que pode significar anúncios para uma existência mais digna de ser vivida, como pessoa/profissional. 
Dessa forma, na ação de arquitetar o ensino remoto, se por um lado alguns problemas do ensino presencial se agravam, por outro, irrompem situações inesperadas, acontecimentos carregados de possibilidade, como citadas nos depoimentos a seguir:

Eu tenho um caso de um aluno que era inquieto, não realizava as atividades de casa, disperso, assim, muito brincalhão e imperativo, [ele] tem demonstrado através dessas atividades, tem uma participação excelente. Realiza todas as atividades, envia todas as devolutivas, participa, cumpre as atividades, grava vídeos, grava áudios, manda as fotos das atividades, pergunta quando tem dúvidas. Foi uma revelação esse aluno (Prof.a 09).

As crianças não só mandam fotos, como passaram a mandar vídeos das tarefas: tanto em tempo real, fazendo-as, como a gravação de leituras de textos. Esses elementos foram sendo incorporados ao trabalho e hoje, dois meses depois de iniciarmos esta experiência, a maioria das crianças já participa ativamente das aulase a aceitação e engajamento dos pais está mais evidente, pois, caminhando juntos, estamos abrindo novos caminhos (Prof.a 10).

Os dois relatos expressam alguns ganhos do processo, "uma revelação" em termos de empenho e desempenho de alguns estudantes. $O$ segundo enunciado destaca, igualmente, o "engajamento" das famílias no acompanhamento das crianças. Tais acontecimentos reiteram o caráter incerto, delicado, imprevisivel e multifacetado da educação (Contreras Domingo, 2015).

As afirmações das professoras indicam, ainda, a utilização de estratégias de ensino até então desconsideradas na prática pedagógica das escolas. Fotos, vídeos, gravação de áudios, gravação de leitura de textos - de autoria dos estudantes e enviados para as professoras -evidenciam um movimento peculiar da situação estabelecida pelo ensino remoto. Certamente, "esses elementos foram sendo incorporados ao trabalho" e constituem alterna- tivas metodológicas que doravante farão parte da dinâmica do trabalho docente, expressos na assertiva citada acima de que "estamos abrindo novos caminhos".

As professoras, citadas a seguir, destacam essa possibilidade de utilização dos novos recursos tecnológicos no retorno ao ensino presencial:

[...] porque [o ensino remoto] nos chamou atenção pra utilizar de repente outras ferramentas, outros mecanismos que a gente não utilizava antes, que a gente até pode tá utilizando quando terminar a quarentena, quando tiver as aulas presenciais, a gente pode até tá utilizando pra tá dando uma orientação maior e melhor (Prof.a 02).

O ensino remoto vem contribuindo até para isso, para a gente também descobrir que o celular pode ser usado como ferramenta do processo de ensino e aprendizagem. Essa tem sido uma das vantagens, eu acho. Posso até não estar totalmente correta, mas no momento eu percebo isto (Prof.a 09).

Importa sublinhar que, apesar da exigência de incorporação das novas tecnologias no processo de ensino e aprendizagem não constituir novidade, o contexto atual obrigou sua utilização de forma urgente e como principal alternativa para continuidade do trabalho pedagógico. Alguns docentes enxergam, ainda, como possibilidade ocasionada pelo ensino remoto, um reconhecimento do trabalho do professor e da escola: "Então eu não sei se eu tô sendo otimista, mas eu acredito que socialmente isso mostra o quanto o trabalho dos professores, das professoras é relevante pra nossa sociedade" (Prof. 05). O mesmo professor afirma que o ensino remoto tem constituído um tempo/ espaço para reflexão:

[...] eu tenho, na verdade aprendido mais refletindo sobre essas questões do que aprendido de forma prática como usar uma determinada coisa, sabe? E aí eu tenho refletido bastante sobre essas questões de ensino à distância, de ensino 
remoto, de questões de poder relacionadas a tudo isso... e questões políticas mesmo e os impactos do trabalho com tecnologias digitais no dia a dia dos professores e das professoras [...].

Assim, as narrativas denotam que o ensino remoto, ou ensino emergencial, pode ser caracterizado como um tempo em que a complexidade, a contradição, a incerteza, a fragilidade e a potência da educação, da escola e, por consequência, do trabalho docente, assumem maior dramaticidade. Mas desvelam, igualmente, a plasticidade dos professores ao tirarem proveito do cenário perverso que toma conta do seu dia a dia, refletindo, inquietandose, enxergando e projetando contextos afirmativos para seu fazer.

\section{Considerações inconclusas}

Os elementos que orientaram as reflexões aqui desenvolvidas se circunscrevem em um tempo histórico que apreende relações sociais, políticas, econômicas e culturais envolvidas em um processo de enfrentamento a um conjunto de desafios, dentre eles a luta pela vida, mas sem deixar de lado o trabalho docente e o compromisso profissional de acompanhar os(as) estudantes no desenvolvimento de atividades escolares, dando continuidade aos vínculos entre escola e estudantes.

Dentre os entraves enumerados, a forma de organização do trabalho e as condições dadas para realizá-las se expressam como fragmento de uma realidade sócio-histórica e pedagógica, até então inusitadas. Os meios através dos quais a instituição escolar, orientada pela normatividade do Ministério da Educação, geriu o processo de sistematização de ensino remoto, revela um "alinhavo" para garantir certa normalidade a algo que é totalmente fora do normal. Em uma busca desenfreada para tornar possivel a realização do trabalho, a escola assume para si a responsabilidade de instâncias superiores - Secretarias de Educação Municipal e Estadual e Ministério da Educação - e coloca sob a responsabilidade docente os afazeres pedagógico-administrativos do ensino remoto.

Assim, os(as) docentes expressam o enfrentamento de inúmeros desafios ligados à incorporação das novas tecnologias, ao acompanhamento individual das crianças e até das suas famílias, ao cumprimento das variadas demandas pedagógicas e burocráticas; e os dilemas éticos por não conseguirem chegar a todos, além de conflitos, angústias, sobrecarga e descrença na eficácia do que estão realizando. Denotam, igualmente, seu engajamento, seu compromisso e responsabilidade com seu oficio que tem como centralidade o cuidado com a vida, sendo a educação sua dimensão fundamental.

Nessa perspectiva, longe de sucumbir ao contexto desfavorável, os(as) professores(as) encontram estratégias, resistem e (re)existem na docência à distância, de modo a efetivar e reafirmar a sua profissionalidade, na tentativa de dar continuidade ao direito dos(as) estudantes à educação, ainda que atravessados(as) pela angústia de estar acompanhando apenas uma parte deles(as).

Expressando a capacidade humana de transformar o vivido em experiência, dimensionada pela temporalidade, interpretação e ressignificação, emergem das narrativas projeções, reflexões, inquietações, aprendizagens e possibilidades para um devir no campo pedagógico mais próximo das famílias e de um uso mais efetivo das novas tecnologias. Portanto, apesar do quadro social, econômico e educacional atual não se mostrar muito promissor, é de se esperar que a pandemia ainda seja capaz de nos ensinar a formular as perguntas primordiais, para além do "como fazer aula on-line", dentre elas: "Que sociedade e educação são necessárias para termos uma vida que valha a pena ser vivida?"; "Que outra escola é necessária e possivel?". 


\section{Referências}

ARROYO, Miguel. O humano é viável? É educável? Revista Pedagógica, Chapecó, v. 17, n. 35, p. 21-40, maio/ago. 2015. Disponivel em: https://bell.unochapeco.edu.br/revistas/index.php/pedagogica/ article/view/3052 Acesso em: 3 jun. 2020.

BERTAUX, Daniel. Narrativa de vida: a pesquisa e seu métodos. Natal: EDUFRN; São Paulo: Paulus, 2010.

BRASIL. Parecer CNE/CP no 9/2020. Disponível em: http:/ / portal.mec.gov.br/. Acesso em: 15 maio 2020.

CASSIO, Fernando; CARNEIRO, Silvio. 0 descaso genocida e o cinismo: é hora de falar da educação como bem público. 2020. Disponível em: https:// diplomatique.org.br/e-hora-de-falar-da-educacaocomo-bem-publico/. Acesso em: 3 jun. 2020.

COLEMAX. Em defesa da educação pública comprometida com a igualdade social: porque os trabalhadores não devem aceitar aulas remotas. 2020. Disponivel em: http://www.colemarx.com.br/wp-content/uploads/2020/04/Colemarx-texto-cr\%C3\%ADtico-EaD-2.pdf. Acesso em: 2 jul. 2020.

CONTRERAS DOMINGO, José. Profundizar narrativamente la educación. In: SOUZA, Elizeu Clementino de (org.). (Auto)biografias e documentação narrativa: redes de pesquisa e formação. Salvador: EDUFBA, 2015. p. 37-61.

DELORY-MOMBERGER, Christine. Abordagens metodológicas na pesquisa biográfica. Revista Brasileira de Educação, v. 17, n. 51, p. 523-536, dez. 2012.

A pesquisa biográfica ou a construção compartilhada de um saber do singular. Revista Brasileira de Pesquisa (Auto)biográfica, Salvador, v. 1, n. 1, p. 133-147, jan./abr. 2016. Disponível em: https: / / www.revistas.uneb.br/index.php/rbpab/article/view/2526 Acesso em: 5 jun. 2020.

FERRAROTI, Franco. Sobre a autonomia do método (auto)biográfico. In: NÓVOA, António; FINGER, Mathias. 0 método (auto) biográfico e a formação. Natal: EDUFRN; São Paulo: Paulus, 2010. p. 33-57.

GOODSON, Ivor. Currículo, narrativa e o futuro social. Rev. Bras. Educ. v. 12, n. 35, p. 241-252, maio/ ago. 2007. Disponivel em: https://www.scielo.br/ pdf/rbedu/v12n35/a05v1235.pdf. Acesso em: 5 jun. 2020.

HUBERMAN, Michael. Trabajando con narrativas biográficas. In.: McEWAv, Hunter; EGAN, Kieran (comp.). La narrativa en la enseñanza, el aprendizaje y la investigación. Buenos Aires: Amorrortu, 2005. p. 183235.

NÓVOA, António. Formação de professores e trabaIho pedagógico. Lisboa: Educa, 2002.

PASSEGGI, Maria da Conceição. Memoriais autobiográficos: escritas de si como arte de (re)conhecimento. In: CORDEIRO, Verbena Maria Rocha; SOUZA, Elizeu Clementino de (org.). Memoriais, literatura e práticas culturais de leitura. Salvador: EDUFBA, 2010. p. 19-42.

PASSEGGI, Maria da Conceição. Narrativas da experiência na pesquisa-formação: do sujeito epistêmico ao sujeito biográfico. 2016. Disponível em: https:// portalperiodicos.unoesc.edu.br/roteiro/article/view/9267/pdf. Acesso: 30 jun. 2020.

PASSEGGI, Maria da Conceição; ROCHA, Simone Maria da. A pesquisa educacional com crianças: um estudo a partir de suas narrativas sobre o acolhimento em ambiente hospitalar. Revista Educação em Questão, Natal, v. 44, n. 30, p. 36-61, set./dez. 2012. Disponivel em: https://www.periodicos.ufrn. $\mathrm{br} /$ educacaoemquestao/article/view/4080. Acesso em: 5 jun. 2020.

SANTOS, Boaventura de Sousa. A Cruel Pedagogia do vírus. Coimbra: Edições Almedina, 2020.

SOUZA, Elizeu Clementino de. Diálogos cruzados sobre pesquisa (auto)biográfica: análise compreensiva-interpretativa e política de sentido. Educação, Santa Maria, v. 39, n. 1, p. 39-50, jan./abr. 2014. Disponivel em: https://periodicos.ufsm.br/index.php/ reveducacao/article/view/11344. Acesso em: 3 jun. 2020.

SOUZA; Elizeu Clementino de; MEIRELES, Mariana Martins de. Olhar, escutar e sentir: modos de pesquisar-narrar em educação. Revista Educação e 
Cultura Contemporânea, v. 15, n. 39, p. 282-300, 2018. Disponivel em: http://revistaadmmade.estacio.br/ index.php/reeduc/article/viewArticle/4750. Acesso em: 16 jun. 2020.

TONUCCI, Francisco. Não vamos perder esse tempo precioso dando lições de casa. Diário El País. Abril de 2020. Disponivel em: https://elpais.com/socie- dad/2020-04-11/francesco-tonucci-no-perdamos -este-tiempo-precioso-dando-deberes.html. Acesso em: 15 dez. 2020.

Elzanir dos Santos é doutora em Educação Brasileira pela Universidade Federal do Ceará (UFC). Realizou estágio douto$\mathrm{ral} /$ sanduiche na Universidade de Lisboa/Instituto de Educação, em Portugal. Realiza pós-doutorado no Programa de Pós-Graduação em Educação e Contemporaneidade (PPGEduC) da Universidade do Estado da Bahia (UNEB), no âmbito do Grupo de Pesquisa (Auto)Biografia, Formação e História Oral (GRAFHO). Professora associada do Departamento de Metodologias da Educação/Centro de Educação da Universidade Federal da Paraíba (UFPB). Vice-líder do grupo Currículo, Formação de Professores e Pesquisa (Auto)Biográfica (GPCFORPAB).E-mail: elzaniridentidade@gmail.com

Idelsuite de Sousa Lima é doutora em Educação pela Universidade Estadual de Campinas (Unicamp), professora associada da Universidade Federal da Paraíba (UFPB), com exercício no Departamento de Metodologia da Educação desta instituição. É líder do grupo de pesquisa em Currículo, Formação de Professores e Pesquisa (Auto)Biográfica (GPCFORPAB) e editora da Revista Espaço do Currículo. E-mail: idel.lima@uol.com.br

Nadia Jane de Sousa é doutora em Educação pela Universidade Federal da Paraíba (UFPB). Professora associada da UFPB. É membro do Grupo de Pesquisa em Pedagogia, Trabalho Educativo e Sociedade (GEPPTES).E-mail: janenadia@ gmail.com 